\title{
UMA CANTIGA NA NOITE DO MEU AMIGO
}

\author{
Elisabete Carvalho Peiruque*
}

\begin{abstract}
RESUMO: O artigo aborda a especificidade das Cantigas de Amigo características da lírica trovadoresca da Peninsula Ibérica, considerando a sua emergência e sua origem pagã dentro do panorama social da Idade Média dominado pela ideologia da Igreja Cristã. O inusitado desta poesia que fala da mulher, do amor e da sexualidade vivida livremente está no fato de que isto tenha ocorrido no contexto religioso de Santiago de Compostela. O erotismo presente nas Cantigas é motivo de indagações apoiadas no campo da história as quais permitem pensar em representações de um imaginário de liberdade frente à repressão da Igreja.
\end{abstract}

PALAVRAS-CHAVE: Cantigas de Amigo - Erotismo - Igreja Cristã

ABSTRACT: This article comments the originality of the troubador medieval poetry. It considers its paganism in opposite of christian ideology because this poetry tells about the women, the love and the sin. The eroticism present in the Cantigas is curious and maybe represents a liberty imaginary against repression of the Church.

KEYWORDS: Medieval Poetry-Eroticism - Christian Church

Sen meu amigo manh'eu senlheira e sol non dormen estes olhos meus e, quant'eu posso, peç'a luz a Deus e non mi-a da per nulha maneira, mais, se masesse com meu amigo a luz agora seria migo.

Quando eu com meu amigo dormia, a noite não durava nulha ren, e ora dur'a noit'e e vai e vem, non vem a luz, nen pareç'o dia, mais, se masesse com meu amigo, a luz agora seria migo

(BOLSEIRO. In: NUNES, 1972, p. 356)

A sugestiva e encantadora cantiga de Juian Bolseiro, da qual lemos as duas primeiras estrofes, mostra poeticamente uma pequena parte do universo das relações amorosas vividas na baixa Idade Média - ou pelo menos de sua concepção no terreno do imaginário -, deixando claro o que se tem como pressuposto das cantigas de amigo, isto é, elas são o produto de uma cultura pagã como que ilhada no mundo medieval marcado pela força da Igreja cristã. A bela cantiga, uma das mais de cinco centenas que compõem o corpus das cantigas de amigo produzido no noroeste da Península Ibérica,

\footnotetext{
*Doutora em História - UFRGS - Instituto de Letras - peiruque@yahoo.com.br.
} 
deixa explícita a liberdade vivida pelos homens e mulheres nas suas experiências amorosas, o que, se não é exatamente verdade em todos os sentidos, o é como representação de desejos e sonhos coletivos de uma sociedade evidentemente letrada. Abordando textos literários medievais, Georges Duby (1988, p. 159) conclui que o imaginário "forçosamente, não se afasta tanto do real", e Lucien Boia (1998, p. 27) o vê como um diálogo com o real.

Lembremos que, no caso das cantigas de amigo, estamos frente à poesia culta, apesar dos temas populares. Tavani (2002, p. 193) considera tal corpus poético como "resultado de uma sábia elaboração artística". O poeta, dentro de um esquema de refrão que as cantigas mais elaboradas guardam ainda como marca popular, reitera o tempo da espera amorosa numa antecipação do tempo proustiano, ao assinalar o tempo que flui nos bons momentos, ocorrendo o oposto como contrapartida. Percebe-se um clima em que o pecado do sexo não existe pela sinceridade de um discurso poético feito de uma dupla sensibilidade. Sendo poesia feita por homens, a lírica de amigo é amostra de uma sensibilidade emergente que dá conta dos sentimentos femininos e masculinos. A cantiga de amigo é a representação de um mundo masculino que não rejeita a figura feminina, como o que se verifica na sociedade cristã misógina da Idade Média, pelo menos em termos de discurso.

O que se lê nesta cantiga está de forma recorrente em dezenas de outras. Os vários estados amorosos que ali estão representados apontam para a finura de espíritos que conhecem a psicologia feminina por serem parceiros dos mesmos sentimentos. As situações em que há referências mais claras ou mais sugestivas de uma experiência sexual vivida são várias também. É exatamente esta marca que permite afirmar a origem pagã das cantigas pelo que se sabe da rigidez da Igreja em relação à sexualidade, considerada sempre como luxúria. $\mathrm{O}$ que se infere deste conjunto, que é único na literatura ocidental (TAVANI, 2002), é a expressão de sua vivência sem sugestão de licenciosidade.

Sendo poesia culta, oriunda, portanto, de uma sociedade letrada, podemos colocar uma pergunta: o que teria motivado a escrita desse delicado corpus poético? Ou seja, o que teria levado aqueles trovadores e jograis ibéricos de quem conhecemos os nomes a escreverem em nome de mulheres, traduzindo-lhes as sensibilidades? $\mathrm{O}$ tom que passa pelo todo das cantigas sugere um olhar terno para este mundo onde inexiste a noção de pecado que marca o mundo cristão. A admiração perceptível faz pensar no mundo rural e sua resistência às práticas cristãs impostas. Mais ainda: sabe-se que o cristianismo na Idade Média foi uma religião urbana de um mundo minoritariamente urbano (LE GOFF, 1995, p. 103-106) e, deste modo, pode-se inferir que a resistência seria também - ou quem sabe principalmente - da sociedade letrada e cristã, colocada entre a força da Igreja nos núcleos urbanos da Galícia e as comunidades camponesas vivendo a cultura folclórica, porque afastadas da maior influência da cristianização. Régine Pernoud (1981, p. 114), na sua visão mais que favorável à Idade Média, aponta na poesia medieval o que ela chama de trocas sociais fecundas. "A seiva poética circulava livremente e enriquecia-se com tudo aquilo que o povo lhe podia trazer de vigor e a alta sociedade, de requinte". Os exemplos da historiadora provêm da literatura francesa, ainda que seja difícil imaginar que na poesia dos trovadores provençais houvesse alguma contribuição popular. Contudo, seu ponto de vista ajusta-se bem à poesia de amigo, composta por gente que dominava a língua e conhecia regras poéticas para expressão de sensibilidades, estando vinculada - ou não - ao extrato aristocrático.

Considerando que nestes dois ou três primeiros séculos do milênio a 
cristianização já começa a ser uma realidade e que as cantigas florescem numa região muito próxima de Santiago de Compostela, é possível pensar em restos de uma cultura em extinção, ou, quem sabe, até algo que já seria apenas memória e que, no entanto, era ainda significativo, o suficiente para ser visto como ideal. Poderíamos colocar como uma outra hipótese a possibilidade deste mundo de liberdade jamais ter existido e, assim configurar apenas o sonhado, nos moldes do fantástico país de Cocanha. Entretanto, como diz Hilário Franco Jr (2003, p. 109), "não se imagina o que se quer, mas somente o que é possível imaginar". Em relação às próprias cantigas, Giuseppe Tavani (2002, p. 35) considera a probabilidade do seu fundo "ser uma autêntica experiência do real, ainda que resolvida num facto poético já isolado de toda e qualquer ligação com a realidade e elevado a paradigma". Ao aludir à separação entre um real vivido e a sua representação ao nível do estético, é de se pensar numa consciência de abstração que Wilhelm Worringer (apud LIND, 1970, p. 248) vê como "ponto de partida e a finalidade de toda a arte", o que remete à intencionalidade da arte das cantigas de amigo na sua aparente simplicidade formal. Igual é o pensamento de Octavio Paz sobre a emergência da lírica provençal:

Ao comporem suas canções de amor, [os poetas] cumpriam uma função social. Mas é evidente, também, que os sentimentos e idéias que aparecem em seus poemas correspondiam de algum modo ao que pensavam, sentiam e viviam os senhores, as damas e clérigos das cortes feudais. (PAZ, 1994 p. 81)

Portanto, podemos falar de um clima mental generalizado nesta Europa medieval dos séculos XII e XIII em que a poesia trovadoresca, por um lado, e o mito de Tristão e Isolda, por outro, começam a "inventar o amor romântico" - para usar da expressão de Howard Bloch, subtítulo de sua obra de 1995 -, constatação que também leva a pensar em convenções sempre presentes no discurso artístico de cada época. Não se pode esquecer que a criação dessas no terreno da arte não é aleatória; as convenções são produzidas em e por determinado contexto. No estudo que faz das imagens como uma via para o conhecimento histórico, Peter Burke (2004, p. 237) assinala a importância de se examinar séries de imagens e não cada uma isoladamente. O grande corpus das cantigas - uma série de imagens verbais, literárias - pela sua reiteração, apresenta esta face de uma sociedade para quem falar do amor vivido em liberdade deve ter sido fundamental. Com isto, também se tem as pontas do processo lento, porém irreversível, da percepção que o homem medieval vai adquirindo de si próprio.

O que parece certo é que, presente ou passada, a vida vivida nessas comunidades ainda intocadas pelo cristianismo - e a noção que é intrínseca a esse da sexualidade sempre manchada pelo pecado da luxúria, - deveria significar algo para as sociedades cristãs, talvez um modelo distante para o sonho. Há no todo das cantigas uma adesão dos poetas à vida sentimental dos homens e mulheres que aí viveriam ou já teriam vivido. Sente-se nelas um olhar de afeto, o que faz com que estes pequenos poemas, às vezes quase ingênuos - ou aparentemente ingênuos -, sempre remetam para uma idéia de felicidade e realização amorosa, mesmo que, muitas vezes, haja uma lamentação pelos desencontros. A visão que as cantigas passam é sempre de um amor vivido, concretizado ou em vias de o ser. O poeta derrama sua ternura por este mundo, talvez conhecido por ouvir contar - ou tão inventado como Cocanha -, fazendo-o belo por ser esta a sua visão do amor, expressão de seus desejos, aí vistos pelo eu lírico feminino. Podem ser também expressão de nostalgia por um mundo que desapareceu ou que está 
em vias de extinção e absorção pelo cristianismo.

As cantigas são representação de um imaginário de liberdade, liberdade ampla, num tempo em que a Igreja se impunha com força cada vez maior: liberdade de viver o amor, a atração, a sexualidade sem culpa. Morin (1999) lembra que a permanência da atração sexual entre homem e mulher constitui uma das marcas da hominização. As cantigas representam o conjunto de sensibilidades coletivas de um tempo específico de uma sociedade que, de modo geral, foi altamente repressiva. Assim podemos vê-las como aquilo com que sonharam os homens e mulheres da Galícia medieval. Quem sonha, sonha com o que gostaria de ter, com o que está no terreno do desejado. Nas cantigas, é possível ler os anseios de uma sociedade que buscou o seu modelo naquilo que consideraria ideal. Pensemos mais uma vez, no fato surpreendente que foi a sua produção ocorrer na proximidade de Santiago com tudo o que o famoso santuário representou de força da Igreja.

Lembre-se a conhecida asserção de Pound a respeito da poesia e dos que a fazem: os poetas são antenas da raça. O simbolismo de antena, como um mecanismo que capta algo em primeiro lugar, remete para os primeiros séculos do milênio, quando está se iniciando lentamente a consciência do homem na sua individualidade diferenciadora do grupo. Da mesma forma, Hoog (1992, p. 17), ao comentar o simbolismo do Graal, refere-se aos poetas e aos sonhadores como aqueles que "sabem escutar em si mesmos a voz coletiva dos mitos ancestrais". Para Le Goff (1983, p. 247), "a pessoa constrói-se ao nível da afetividade, da sensibilidade, da emoção". É uma testemunha disto, como já foi assinalado, a lírica trovadoresca surgida no sul da França, depois irradiada pelo resto da Europa. São os sentimentos expressos de forma poética, carregando muito do imaginário certamente, que aí estão apontando para sensibilidades coletivas e individuais emergentes e colaborando para a conquista de uma consciência da individualidade.

Escreve-se sobre a sexualidade livre porque o que se tem na cultura cristã é o estigma do pecado da luxúria para qualquer manifestação daquela. O poeta - e pensemos nos muitos poetas que ao longo do século XIII continuaram a fazer cantigas de amigo, já estando na Península Ibérica de muito tempo a influência provençal - o poeta, pois, representa com suas cantigas o que gostaria de viver na sua coletividade. Lembre-se que o imaginário é uma resposta ao mundo real e, portanto, não estabelece uma simetria aparente com o representado (BOIA, 1998). As carências de um mundo oprimido são captadas em um discurso poético representativo de um universo onde elas não existem.

$\mathrm{O}$ que se pode inferir deste extrato pagão produzido numa área que, por definição, está na órbita de um dos maiores santuários e local de peregrinação da Idade Média? A origem celta que se costuma atribuir às cantigas escritas em galego-português não é algo dado como definitivo. O historiador português Carlos Fabião (s.d., v I, p. 169) faz ver que os celtas na Península Ibérica radicaram-se mais para o sul, isto é, na zona do Alentejo e no Algarve, "ou seja, precisamente aquela que não costuma ser atribuída àquele povo em diversas obras de duvidosa base científica". Tendo em vista que o território ibérico foi caminho ou terra de assentamento de variadíssimas culturas, é possível pensar em camadas superpostas de práticas pagãs. Considerada a longa duração dos processos históricos, talvez os celtas tivessem deixado marcas de sua passagem mais ou menos demorada pelo território, antes de avançarem para o sul. $\mathrm{O}$ historiador Venceslas Kruta (1989, p. 109) afirma que os celtas deixaram o cenário histórico por volta do século I. No entanto, "seu desmembramento foi apenas um fim aparente. Mesmo na parte ocupada pelos germanos (...) a tradição céltica mantém um 
certo vigor".

De qualquer forma, ficam perguntas: esta região estaria ainda intocada pela pregação cristã ao tempo das cantigas, ainda que próxima de núcleos urbanos de onde saíram os poetas? Tais núcleos, pequenos com certeza, estariam sofrendo pressões para abandonarem crenças primitivas e se converterem? Ou já seriam convertidos superficialmente e olhariam - quem sabe recordariam ou inventariam - um mundo diverso daquele que a Igreja ia criando? Quanto à hipótese de uma origem árabeandaluza, contestada por Tavani (2002, p. 39), também ela não responde à questão da emergência de um extrato poético como o da lírica de amigo num contexto cristão. Pois o que se vê no conjunto das cantigas de amigo é alguma coisa que nega o cristianismo e a sua visão sobre a mulher como aquela que induz o homem ao pecado. Se foi simplesmente de experiência poética, por que a Igreja não conseguiu extirpá-la?

Ora, além do erotismo, mais ou menos explícito, que perpassa o todo das cantigas de amigo, há uma outra marca que uma leitura mais atenta vai revelar, de certa forma relacionada com aquele. São as expressões de auto-elogio pela voz feminina que ocorrem freqüentemente. São elogios à própria beleza, às formas do corpo. "Fremosa e de mui bom prez", "amiga fremosa e mesurada", "fremosa e bom semelhar", "bem talhada", "de bom parecer", "corpo velido", "corpo delgado" são alguns exemplos. Poderíamos pensar numa falta de modéstia que as mulheres representadas demonstrariam no seu comportamento amoroso. Igualmente podemos pensar na necessidade de versificação, número de sílabas por verso. No entanto, são vezes demais para que se considerem estas possibilidades apenas, sem que isto queira dizer que elas não ocorram nunca. Entretanto, sabendo da autoria masculina, parece bastante possível pensarmos aquelas expressões como emanadas do homem que existe no poeta, algo que configuraria a autoria masculina, apontando para a atração do homem pelo corpo feminino que o erotiza. São representações de um olhar masculino infiltradas no pseudodiscurso feminino. Tais marcas seriam indicativas da procedência masculina, caso não a tivéssemos como um dado. Nos muitos estudos a respeito das cantigas de amigo, parece que a obra recente de Tavani (2002) é a única a mencionar aquele dado tão significativo, sem, contudo, levar adiante uma análise do possível sentido. As expressões "panegíricas", para ele, "vão no sentido de uma mais acentuada corporalidade da mulher" (ibid., p. 209). E é evidente que falar do corpo já é estar no terreno da sexualidade e da atração que o feminino exerce sobre o masculino.

Deste modo, pois, as cantigas, como produto de um olhar carregado de afetividade pela mulher, mostram-na como dona de um corpo desejado. As sensibilidades pelos sentimentos femininos não anulam a sexualidade presente, como o faz a cultura cristã que vê na mulher a representação do pecado, a continuidade da Eva tentadora. A história é pródiga em registros sobre a condição feminina marcada pelo mal e para a depreciação. Atente-se para as associações que um monge espanhol, Luís de Granada (apud DELUMEAU, 2003) estabelece, já em meados do século XIV entre Eva e o pecado. Para ele, o apetite sensitivo é Eva dentro de nós, é "a parte mais débil e mais inclinada de nossa alma, pela qual a antiga serpente ataca nosso Adão interior" (ibid., p. 50). É longa a vida dos clichês, como diz Pernoud (1981) ao falar do papel destacado, porém ignorado, de tantas mulheres no contexto das cruzadas. O que a visão pagã revela é uma visão integral da mulher, uma não-dissociação entre corpo e espírito como a que é feita pelo cristianismo, opondo-se ao paradoxo em que viveram os cristãos da Idade Média que, negando à mulher a condição de ser íntegro, não podiam negar que o salvador do mundo nascera de um desses seres execrados. 
Para Georges Duby, citado por Badinter (1986), as mulheres no século XII - o autor fala apenas da nobreza que deixou registros - são mais objeto de distração do que de consideração. É ainda o mesmo medievalista que afirma que "os textos da Idade Média dedicaram-se a mostrar que a igualdade entre o homem e a mulher era uma heresia" (ibid., p. 103). Quais textos, poderíamos perguntar. É impossível pensar as cantigas de amigo dentro deste conceito e, se elas representam um momento de consideração e respeito pela mulher, cabe a pergunta de Badinter (ibid., p. 123): "se existiram lugares e épocas em que as mulheres tiveram prestígio e alguns poderes, como e por que permitiram que lhes tirassem tudo?".

Wagner (1994, p. x, xi) mostra que, de acordo com toda a evidência acumulada, nas sociedades que viviam em regiões onde eram abundantes as terras cultiváveis, "a mulher gozava de alta estima e consideração social". Nestas sociedades, sendo essencial o trabalho feminino, pois o homem saía em busca de outras fontes de sobrevivência, ou para as suas atividades guerreiras, a subsistência seria menos crucial por conta de formas mais simples de cultivo, passíveis de serem realizadas pela mulher. Porém, diz Wagner, quando o produto da terra começou a ser obtido através do cultivo intensivo, muitas vezes em locais distantes da zona de habitação, num tipo de trabalho que exigiria muito mais força, foram os homens chamados a isto por serem mais adequados fisicamente. Opiniões menos favoráveis ao lugar da mulher no contexto social são, entretanto, unânimes quanto ao trabalho feminino e sua participação na economia dos grupos. Mead (apud BADINTER, 1986) aponta, como resultado de suas observações de comunidades nativas, a inexistência de sociedades sem uma divisão sexual do trabalho, sendo a mulher responsável pela agricultura e o homem pela caça, o que não chega a já configurar uma idéia de superioridade masculina. Badinter (ibid.), partindo de estudos de Leroi-Gourhan sobre a arte das cavernas, termina por afirmar que o estudo destes tempos arcaicos nada prova a respeito de um poder tirânico dos homens sobre as mulheres.Tais considerações sobre tempos mais recuados demandam, evidentemente, cautela quanto a inferências. Contudo, tanto quanto a arte pode ser testemunha de um povo e das individualidades que a produziu, é possível pensar, no caso das cantigas, em relações de reciprocidade entre homens e mulheres.

Mattoso (1993), medievalista português, em seus estudos sobre a cultura medieval em seu país, refere-se às zonas litorâneas como opostas - pela sua acessibilidade a influências vindas de fora - àquelas interioranas voltadas para $\mathrm{o}$ pastoreio. As cantigas de amigo descrevem, ainda que não na sua totalidade, paisagens que sugerem zonas próximas ao mar, por onde partem os homens e onde os esperam as mulheres. Essas coletividades, portanto, também vivem de uma economia da terra, ao que tudo indica, exercida por mulheres. A lírica de amigo, onde o homem é ausência, saudade, desejo, refere, freqüentemente, a sua ida para o mar e para a guerra. Aí temos a representação da mulher que espera à beira do mar o homem que virá da pesca ou do "fossado" onde está a serviço do rei.

As cantigas de amigo mostram a mulher vivendo em nível de igualdade com o homem, o que remete para uma visão semelhante, complementar à de Carlos Wagner. Para Barros (2001), a mulher é olhada como superior pela sua capacidade de gerar a vida. A autora comenta a postura de respeito por parte do homem quando este ignorava sua participação na fecundação. Para Leroi Gourhan (apud BADINTER, 1986, p. 41), a ausência de representações do ato sexual e de erotismo na arte das cavernas é indicativa deste desconhecimento. "Mesmo se os homens suspeitassem de sua participação [...] só podia ser uma idéia muito vaga [...] Portanto não está excluída a hipótese de que os 
homens imaginassem a reprodução da espécie como um tipo de partenogênese". Lembrem-se as estatuetas, hoje chamadas de Vênus, descobertas nas escavações arqueológicas: são representações do feminino e de seu poder de fecundidade, apresentando o ventre dilatado pela vida que carregava dentro de si. É ainda possível recordar que a feminilidade era apreciada pelos romanos como um poder sobrenatural, o que se lê, por exemplo, em um texto de Plínio, o Velho (apud FURNARI, 1995, p. 58). A presença romana na península desde antes da era cristã é, possivelmente, responsável por uma das camadas do vasto extrato cultural subjacente à cultura cristã e contribui para pensar num paganismo duradouro bem como nas posturas relativas à mulher, situação frontalmente oposta àquela onde a Igreja firmara seu poder.

A intromissão de uma voz masculina por excelência no interior das cantigas dá conta de um imaginário masculino. Poder olhar e sentir prazer com o corpo feminino era algo vedado numa sociedade onde a mera imaginação já constituía pecado. Terão os trovadores e jograis olhado este mundo em extinção com os olhos verdadeiros ou com os da memória? Quem sabe alguns estariam ainda no primeiro caso e ao final do trovadorismo já se teria apenas a lembrança conservada como relíquia. Ou terá sido sempre apenas sonho? Aqueles homens falam assumindo os sentimentos femininos que dizem respeito aos masculinos; falam como homens também porque estão representando através de uma imagem não só os anseios de uma coletividade, mas igualmente de sua parcela masculina. Se a Igreja não interferiu neste fazer poético tão expressivo, não se pode deixar de questionar por que ficou ausente quando da recolha, provavelmente já na metade do século XIV. Tal fato talvez significasse sua adesão velada ao tema das cantigas. Sabe-se da pouca religiosidade dos cônegos de Santiago de Compostela (TAVANI, 2002) e sabe-se também que o fato de o pecado da carne ser combatido à base de ameaças infernais mostra que a luxúria estava "na ordem do dia", repetindo a expressão de Mongelli (1994, p. 147). As cantigas de Santa Maria, ao contarem as maravilhas operadas pela Virgem Maria, trazem à luz inúmeros casos de luxúria cometidos por monges e monjas. A rigor, podemos facilmente imaginar que quem mais pensaria nas mulheres e nos prazeres do sexo seriam os religiosos.

A experiência amorosa vivida, ou antes, sufocada, na sociedade cristã dá origem à criação de imagens verbais diferenciadas das do real vivido. Ninguém pode expressar a sexualidade sem a culpa do pecado e, se o simples imaginar é pecado também, criamse, pois, imagens que estão fora do universo cristão ao qual se pode atribuir uma voz. Como afirma Franco Jr (2003, p. 98), “[...] nenhuma imagem (sequer a moderna fotografia) é descrição do real objetivo. É sempre interpretação, é ampliação ou redução dele [...]". Não podendo expressar o que era verdadeiramente sentido, sofrido, vivido, os poetas, traduzindo os anseios das coletividades, representam-no metaforicamente. $\mathrm{O}$ diálogo que as representações do imaginário estabelecem com a realidade do século XIII na Galícia medieval revela as sensibilidades de um mundo atormentado que se deseja a si mesmo libertado. E também a visão de homem - aqui especificamente gênero masculino -, liberado para viver o erotismo que o corpo feminino desencadeia. Referindo-se às realidades dos imaginários, Franco Jr (ibid., p. 105) conclui que são "formas próprias de os homens verem o mundo e a si mesmos, criam elos, geram e mantêm os grupos, despertam a consciência social".

O cruzamento de imaginários gerados numa mesma sociedade, repressiva por princípio e fim, constitui no seu todo um discurso de enfrentamento de culturas. Neste jogo de oposições, em que o paganismo vai sendo absorvido, apropriado pela fé cristã, ao mesmo tempo em que nela deixa suas marcas, podemos ler um diálogo de culturas a 
partir de uma sociedade letrada, que não tem como expressar seus sonhos e apreensões senão no discurso poético. Experiência vivida, observada, retida na memória ou apenas intuída, ou ainda, sonhada - convenção artística como também é -, o que as cantigas representam mostra-se como resposta. A cultura pagã representada é o veículo de que se serve a sociedade cristã, através dos seus poetas, para mostrar sua oposição ao discurso desumano da Igreja em relação ao feminino e à sexualidade.

\section{REFERÊNCIAS}

BADINTER, Elisabeth. Um é o Outro - relações entre homens e mulheres. S.Paulo: Círculo do Livro, 1986.

BARROS, Maria Nazareth Alvim de. As Deusas, as Bruxas e a Igreja - Séculos de perseguição. Rio de Janeiro: Record: Rosa dos Tempos, 2001.

BLOCH, R. Howard. A misoginia medieval - a invenção do amor romântico. Rio de Janeiro: Editora 34, 1995.

BOIA, Lucien. Pour une histoire de l'imaginaire. Paris : Gallimard, 1988.

BURKE, Peter. Testemunha ocular. - história e imagem. São Paulo: EDUSC, 2004.

DELUMEAU, Jean. O pecado e o medo - A culpabilização no Ocidente (Séculos 13 18). Volume I. São Paulo: EDUSC, 2003.

DUBY, Georges. O cavaleiro, a mulher e o padre. Lisboa: Publicações Dom Quixote, 1988.

FABIÃO, Carlos. A II Idade do Ferro. In: MATTOSO, José. (Org.). História de Portugal. Lisboa: Editorial Estampa. s/d, v I.

FRANCO JR, Hilário. O fogo de Prometeu e o escudo de Perseu. Reflexões sobre mentalidade e imaginário. Signum. São Paulo, n 05, p. 73 -116, 2003.

FURNARI, Pedro Paulo. Antiguidade Clássica. A história e a cultura a partir dos documentos. São Paulo, Campinas: UNESP, 1995.

HOOG, Armand. Prefácio. In: DE TROYES, Chrétien. Perceval ou o Romance do Graal. São Paulo: Martins Fontes, 1992.

KRUTA, Venceslas. Os celtas. São Paulo: Martins Fontes, 1989.

LE GOFF, Jacques. O maravilhoso e o cotidiano no Ocidente Medieval. Lisboa: Edições 70, 1983.

. A civilização no ocidente medieval. v I. Lisboa: Editorial Estampa, 1995.

LIND, Georg Rudolf. Teoria Poética de Fernando Pessoa. Porto: Editorial Inova, 1970.

MATTOSO, José. A Cultura Medieval Portuguesa. Lisboa: Imprensa Nacional - Casa da Moeda, 1993.

MONGELLI, Lênia. Por quem peregrinam os cavaleiros da távola redonda. São Paulo: Íbis, 1994.

MORIN, Edgar. Amor, poesia, sabedoria. Rio de Janeiro: Bertrand do Brasil, 1999.

NUNES, J.J. Cantigas de amigos dos trovadores galego-portugueses. Lisboa: Centro do Livro Brasileiro, 1972.

PAZ, Octavio. A dupla chama - amor e erotismo. São Paulo: Siciliano, 1994.

PERNOUD, Régine. Luz Sobre a Idade Média. Lisboa: Publicações Europa-América, 1981.

TAVANI, Giuseppe. Trovadores e Jograis. Introdução à Poesia Medieval GalegoPortuguesa. Lisboa: Editorial Caminho, 2002.

WAGNER, Carlos. Prefácio. In: WAGNER, Carlos e outros (eds). Roles Sexuales - la 
mujer en la historia y la cultura. Madrid: Ediciones Clásicas, 1994. 